
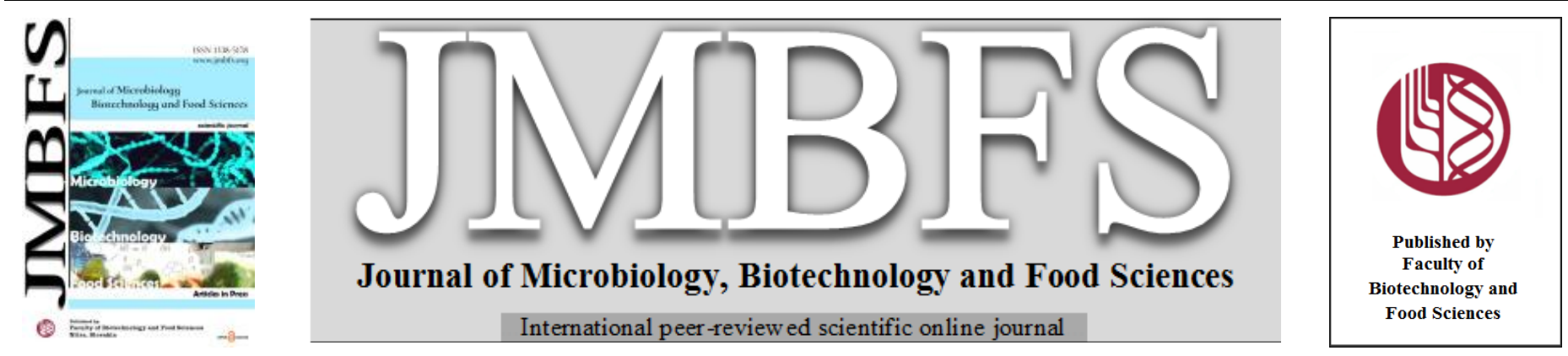

\title{
ASSESSMENT OF THE ANTIOXIDANT POWER OF IN VITRO OBTAINED COLEUS FORSKOHLII BRIQ
}

\author{
Maria Geneva*l, Ira Stancheva ${ }^{1}$, Elisaveta Kirova ${ }^{1}$, Maria Petrova $^{1}$, Saber Hendawy ${ }^{2}$, and Ely Zayova ${ }^{1}$
}

\author{
Address(es): associate professor Maria Geneva, $\mathrm{PhD}$, \\ ${ }^{1}$ Institute of Plant Physiology and Genetics, Bulgarian Academy of Sciences, Acad. G. Bonchev Street, Bldg. 21, 1113 Sofia, Bulgaria. \\ ${ }^{2}$ Medicinal and Aromatic Plants Research Department, Pharmaceutical and Drug Industries Research Division, National Research Centre, 33 El Buhouth Street, Ad \\ Doqi, Dokki, Cairo Governorate 12622, Egypt.
}

*Corresponding author: boykova2@yahoo.com

https://doi.org/10.55251/jmbfs.3840

\section{ARTICLE INFO}

Received 14. 10. 2020

Revised 30. 9. 2021

Accepted 8. 10. 2021

Published 1. 2. 2022

Regular article

OPEN 2 ACCESS

\begin{abstract}
In the present study, a simple protocol for in vitro rooting induction of the important medicinal plant Coleus forskohlii Briq with a high content of secondary metabolites with antioxidant activity was described. For the in vitro germination seeds of $C$. forskohlii were placed on MS medium supplemented with $0.4 \mathrm{mg} \mathrm{L}^{-1}$ gibberellic acid and $1.0 \mathrm{mg} \mathrm{L}^{-1} \mathrm{CaCl}_{2}$. The obtained shoots were cultured on a half-strength $1 / 2$ MS medium containing indole-3-butyric acid (IBA) or indole-3-acetic acid (IAA) at concentrations of 0.1 and $0.5 \mathrm{mg} \mathrm{L}^{-1}$. The maximum rooting of plants $(95 \%)$ with mean values of 9.2 roots per explant, root length $(5.1 \mathrm{~cm})$ and root fresh weight $(0.085 \mathrm{~g})$ was obtained on half-strength MS medium with $0.1 \mathrm{mg} \mathrm{L}^{-1}$ IAA after three weeks of culture. The plants were successfully ex vitro adapted with $93.3 \%$ survival on the mixture substrate of soil, peat and sand $(2: 1: 1 \mathrm{v} / \mathrm{v} / \mathrm{v})$. The antioxidant enzymes activities (superoxide dismutase, catalase, ascorbate peroxidase and guaiacol peroxidase) showed the highest values when IBA was used for $C$. forskohlii in vitro cultivation. Applied auxins influenced the level of secondary metabolites synthesis. Half strength MS culture medium supplemented with $0.5 \mathrm{mg} \mathrm{L}^{-1}$ IAA caused the highest total phenol and flavonoid content as well as the highest antioxidant activity level (radical scavenging activity and ferric reducing antioxidant power). The results indicate that organogenesis is a very complicated biological process involving up and downregulation of plant enzyme and non-enzyme antioxidant protection systems, which play an important role during the organogenesis of plants.
\end{abstract}

Keywords: Coleus forskohlii Briq.; Rooting; Antioxidant activity; Auxin

\section{INTRODUCTION}

The production of plant organs, by organogenesis, directly from meristems is used for the micropropagation of plants. In vitro propagation induced various forms of stresses in plant cells (high humidity, low light intensity, high sucrose and nitrogen concentration, hormonal imbalances in nutrient medium) and lead to reactive oxygen species production, which harms in vitro plant morphogenesis and growth (Benson, 1990). To remove, neutralize and scavenge free radicals and their associated non-radical oxygen species plants developed an antioxidant protection system comprising activation of enzymes (superoxide dismutase (SOD), catalase (CAT) and peroxidases as well as increasing the content of low molecular substrates (phenols, flavonoids, ascorbate, glutathione and $\alpha$-tocopherol) (Larson, 1988).

Several key factors such as the type and the salt strength of the nutritional medium employed and the type and concentration of the plant growth regulators, influence the synthesis of secondary metabolites with bioactive potential into the plant tissue culture (Rao and Ravishankar, 2002; Jamwal et al., 2018). Normally, as a vital chemical component, plant growth regulators in small concentrations possess a specific effect on plant growth - they have a critical role in the regulation of plant cellular processes including controlled plant responses to the abiotic stresses and regulate various physiological and developmental processes during micropropagation (George et al., 2008). The most important plant growth regulators acting either individually or in combination used in plant micropropagation are cytokinins responsible for shoot initiating and auxins, controlling root formation (Gaspar et al., 1996; George et al., 2008). Exogenously applied cytokinins and auxins can regulate many aspects of cell growth and differentiation as well as organogenesis in micropropagated plants and has been implicated in the upregulation of secondary metabolite content in plants (Rao and Ravishankar, 2002; Amoo and Van Staden, 2013). The berberine synthesis in Coscinium fenestratum tissue culture has been stimulated with indole acetic acid (IAA) and naphthalene acetic acid (NAA) (Nair et al., 1992). Given the abovementioned characteristics of plant growth regulators, they can be used to improve the cultivation of medicinal plants that accumulate important bioactive compounds depending on the needs of the pharmaceutical, foods, and cosmetics industries.

Coleus forskohlii Briq (family Lamiaceae) is an important medicinal plant with very good potential to be used in the pharmaceutical and food industry. The diterpene compound forskolin, the major second metabolite, produced mostly in the root cork cells of the $C$. forskohlii is used commercially for the treatment of glaucoma, asthma and several heart ailments, high blood pressure, and some cancers (Wagh et al., 2012; Kamini et al., 2013). In vitro clonal micropropagation of the threatened plant $C$. forskohlii has been developed on Murashige and Skoog (1962) (MS) medium supplemented with $2.0 \mathrm{mg} \mathrm{L}^{-1}$ kinetin and $1.0 \mathrm{mg} \mathrm{L}^{-1} \mathrm{IAA}$ using nodal segments as explants (Sharma et al., 1991) and on MS medium containing $0.46 \mu \mathrm{M}$ kinetin and $0.57 \mu \mathrm{M}$ IAA by culturing stem tip explants (Bhattacharyya and Bhattacharya, 2001). Rooting was obtained upon transfer of shoots onto MS medium containing $1.0 \mathrm{mg} \mathrm{L}^{-1} \mathrm{IAA}$ (Sharma et al., 1991). The leaf base explants generated maximum callusing, shooting and rooting production than that of node and leaf lamina of $C$. forskohlii (Praveena et al., 2012). Effect of auxins in $1 / 2$ MS medium on multiple shoot inductions has been reported in many medicinal plants such as Hyssopus officinalis (Zayova et al., 2018) and Thymus vulgaris (Zayova et al., 2019).

Bioactive molecules such as phenols, alkaloids, terpenoids, flavonoids, and antioxidants, are not only used as flavourings, pharmaceuticals, agrochemicals, fragrances, biopesticides, and drugs but also play a vital role in the plant defence system. It is very important to study the impact of PGRs adding to the nutrient medium on the plants antioxidant capacity during micropropagation. There is a lack of studies on the impact of auxins added to the MS medium on the antioxidant capacity of micropropagated $C$. forskohlii plants. This work aims to provide an effective protocol for in vitro propagation of $C$. forskohlii studying different auxins. The objective of this investigation was also to analyze the effect of investigated auxins on the antioxidant activity of multiple in vitro plants. 


\section{MATERIAL AND METHODS}

\section{Plant material}

The seeds were surface sterilized with soaking in $70 \%$ ethanol for $2 \mathrm{~min}$ and then treated with $15 \%$ bleach solution (commercial bleach) for $15 \mathrm{~min}$ and again washed three times each $15 \mathrm{~min}$ in sterilized distilled water to remove the traces of commercial bleach. For in vitro seed germination of $C$. forskohlii seeds were cultured on an MS medium including vitamins supplemented with $3.0 \%$ sucrose, $7.0 \mathrm{~g} \mathrm{~L}^{-1}$ agar and $0.4 \mathrm{mg} \mathrm{L}^{-1}$ gibberellic acid and $1.0 \mathrm{mg} \mathrm{L}^{-1} \mathrm{CaCl}_{2}$ for three weeks of culture. The in vitro cultures conditions were maintained according to Zayova et al. (2019). Experiments were repeated twice. To induce in vitro roots, the shoots were plated on half-strength MS including vitamins medium with $2.0 \%$ sucrose and 0.1 and $0.5 \mathrm{mg} \mathrm{L}^{-1}$ IBA or IAA, based on preliminary experiments.

For acclimatization under ex vitro conditions, the well-rooted plants were carefully removed from the tubes and washed under running tap water to remove the adhering gelling agent. The plants ( 20 plants per variant) were transferred to small plastic pots ( $8 \mathrm{~cm}$ diameter) containing soil: peat: sand in the volume ratio 2:1:1 $\mathrm{v} / \mathrm{v} / \mathrm{v}$. The potted plants were covered with a transparent polyethylene membrane to ensure high humidity $(90 \%)$ for two weeks. After two months, the percentage of survived plants, plant height and number of leaves were measured. They were maintained in a growth chamber at $20^{\circ} \mathrm{C}$ under $14 \mathrm{~h}$ illuminations $\left(50 \mu \mathrm{mol} \mathrm{m}{ }^{-2} \mathrm{~s}\right.$ $\left.{ }^{1}\right)$ with fluorescent lamps.

\section{Antioxidant capacity}

The enzymes with antioxidant potential superoxide dismutase (SOD), catalase (CAT), ascorbate peroxidase (APX) and guaiacol peroxidase (GPO) were extracted from the plant samples following the method of Hristozkova et al. (2017). Total SOD (EC 1.15.1.1), activity (Giannopolitis and Ries, 1977), CAT (EC 1.11.1.6) activity (Upadhyaya et al., 1985), APX (EC 1.11.1.1) activity (Nakano and Asada, 1987) and GPO (EC 1.11.1.7) activity (Lagrimini, 1997) were determined spectrophotometrically on UV/VIS Спектрофотометър Shimadzu UV-1601. Soluble protein content was determined by using bovine serum albumin as a standard (Bradford, 1976).

For the analysis of the antioxidant compounds $0.3 \mathrm{~g}$ dry samples from three weeks in vitro grown plantlets were ground and suspended in $96 \%(\mathrm{v} / \mathrm{v})$ aqueous methanol. The resulting filtrates were pooled for further processing Concentrations of total phenolic compounds were determined spectrophotometrically using the Folin-Ciocalteu reagent and calculated as caffeic acid equivalents (Pfeffer $\boldsymbol{e t}$ al., 1998). Total flavonoids content in plant tissues were measured spectrophotometrically using the standard curve of catechin (Zhishen et al., 1999). The percentage of radical scavenging activity was measured by colour artificial stable free radical DPPH• (1,1-diphenyl-2-picrylhydrazyl) assay. The changes in colour (from deep violet to light yellow) were read at 517 nm UV-spectrophotometer (Shimadzu, USA)(Tepe et al., 2006). The ferric reducing antioxidant power (FRAP method) depends upon the level of reduction of the ferric tripyridyltriazine (Fe(III)-TPTZ) complex to the ferrous tripyridyltriazine (Fe(II)-TPTZ) by a reductant at low $\mathrm{pH}$ (Benzie and Strain, 1996). Spectrophotometric quantification was used to determine water-soluble (WS-AOM) and lipid-soluble (LS-AOM) metabolites with antioxidant capacity, expressed as equivalents of ascorbate and $\alpha$-tocopherol. (Prieto et al., 1999). This method is based on the reduction of Mo (VI) to Mo (V) by the sample analysis and the subsequent formation of a blue-green phosphomolybdenum complex at acidic $\mathrm{pH}$.

All solvents were analytical. Ascorbate, guaiacol, hydrogen peroxide, DPPH, and ammonium molybdate were obtained from Merck (Germany). Nitroblue tetrazolium, riboflavin, and methionine were purchased from Sigma (United States). All other chemicals were of analytical grade.

\section{Statistical analysis}

The statistical analysis of variance (ANOVA) for comparison of means and significant differences were calculated according to Fisher's least significance difference (LSD) test at the 5\% significance level using a statistical software package (Statgraphics Plus, version 5.1 for Windows).

\section{RESULTS}

\section{Coleus forscohlii micropropagation}

Cultivation of $C$. forskohlii in vitro did not result in bacterial or fung contamination due to successful sterilization with $70 \%$ ethanol (2 min) and treatment with $15 \%$ bleach solution $(15 \mathrm{~min})$. The seedling initiation was performed on MS medium with $0.4 \mathrm{mg} \mathrm{L}^{-1} \mathrm{GA}_{3}$ and $1.0 \mathrm{mg} \mathrm{L}^{-1} \mathrm{CaCl}_{2}$ (Fig. 1a).

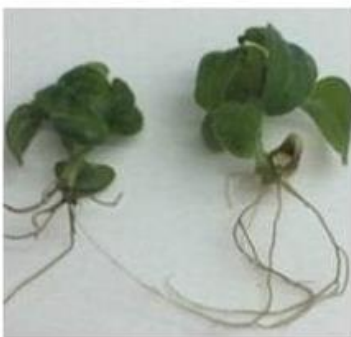

a

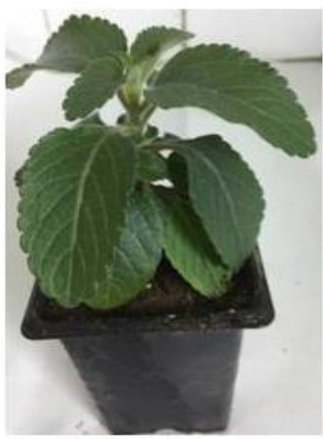

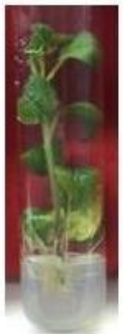

b

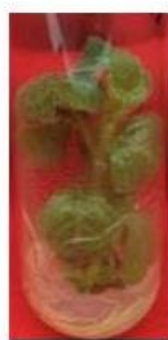

C

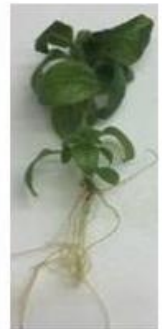

d

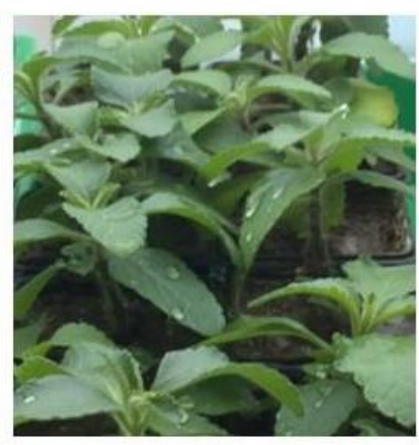

f

Figure 1 Micropropagation of Coleus forscohlii: a) seedling initiation on MS medium with $0.4 \mathrm{mg} \mathrm{L}^{-1} \mathrm{GA}_{3}$ and $1.0 \mathrm{mg} \mathrm{L}^{-1} \mathrm{CaCl}_{2}$; b) rooting on $1 / 2 \mathrm{MS}$ medium supplemented with $0.1 \mathrm{mg} \mathrm{L}^{-1} \mathrm{IBA}$; c) and d) rooting on $1 / 2 \mathrm{MS}$ medium supplemented with $0.1 \mathrm{mg} \mathrm{L}^{-1}$ IAA; e) and f) in ex vitro adapted plants.

Only $20 \%$ of seeds germinated in in vitro conditions. All examined nutrient media stimulated plant growth, shoot development and rooting. After three weeks of culture on $1 / 2$ MS medium supplemented with $2.0 \%$ sucrose and either IBA or IAA (at concentration 0.1 and $0.5 \mathrm{mg} \mathrm{L}^{-1}$ ) maximum growth of the plantlets was observed on $1 / 2$ MS medium with $0.1 \mathrm{mg} \mathrm{L}^{-1}$ IAA - number of plants 1.8 with 10.2 $\mathrm{cm}$ plant length and $0.440 \mathrm{~g}$ fresh weight (Table 1 ).

Table 1 Influence of IBA and IAA added to $1 / 2$ MS medium on the micropropagation of $C$. forskohlii shoots and roots after three weeks of culture

\begin{tabular}{|c|c|c|c|c|c|c|c|}
\hline $\begin{array}{l}\text { Auxin } \\
\mathrm{mg} \mathrm{L}^{-1}\end{array}$ & $\begin{array}{c}\text { Number of } \\
\text { shoots }\end{array}$ & $\begin{array}{c}\text { Plant length } \\
\mathrm{cm}\end{array}$ & $\begin{array}{c}\text { Plant fresh } \\
\text { weight } \\
\mathrm{g}\end{array}$ & $\begin{array}{c}\text { Rooting } \\
\%\end{array}$ & $\begin{array}{l}\text { Number of roots } \\
\text { plant }^{-1}\end{array}$ & $\begin{array}{l}\text { Root length } \\
\mathrm{cm}\end{array}$ & $\begin{array}{c}\text { Root fresh } \\
\text { weight } \\
\text { g }\end{array}$ \\
\hline $0.1 \mathrm{IBA}$ & $1.2 \pm 0.06^{\mathrm{a}}$ & $8.9 \pm 0.44^{\mathrm{c}}$ & $0.298 \pm 0.015^{\mathrm{a}}$ & 95 & $8.0 \pm 0.40^{\mathrm{b}}$ & $4.4 \pm 0.22^{b}$ & $0.062 \pm 0.003^{\mathrm{b}}$ \\
\hline $0.5 \mathrm{IBA}$ & $1.5 \pm 0.07^{\mathrm{b}}$ & $6.1 \pm 0.30^{\mathrm{b}}$ & $0.369 \pm 0.018^{\mathrm{b}}$ & 90 & $6.1 \pm 0.30^{\mathrm{a}}$ & $3.5 \pm 0.18^{\mathrm{a}}$ & $0.033 \pm 0.002^{\mathrm{a}}$ \\
\hline 0.1 IAA & $1.8 \pm 0.09^{c}$ & $10.2 \pm 0.51^{\mathrm{d}}$ & $0.440 \pm 0.022^{\mathrm{c}}$ & 100 & $9.2 \pm 0.46^{\mathrm{c}}$ & $5.1 \pm 0.26^{\mathrm{c}}$ & $0.085 \pm 0.004^{\mathrm{d}}$ \\
\hline $0.5 \mathrm{IAA}$ & $1.6 \pm 0.08^{\mathrm{b}}$ & $5.2 \pm 0.26^{\mathrm{a}}$ & $0.397 \pm 0.02^{\mathrm{b}}$ & 95 & $6.4 \pm 0.32^{\mathrm{a}}$ & $3.9 \pm 0.19^{\mathrm{a}}$ & $0.075 \pm 0.003^{\mathrm{c}}$ \\
\hline LSD & 0.142772 & 0.736059 & 0.0356376 & & 0.738483 & 0.406479 & 0.00580333 \\
\hline
\end{tabular}

are presented as means of 20 plants per after performing ANOVA multifactor analysis

Roots occurred 4-5 days after subcultivation of the plants The highest frequency of rooting (100\%) was observed also on $1 / 2 \mathrm{MS}$ medium with $0.1 \mathrm{mg} \mathrm{L}^{-1}$ IAA in terms of the number of roots 9.2 , root length of $5.1 \mathrm{~cm}$ and fresh weight $0.085 \mathrm{~g}$ (Fig. 1c, d). Half strength MS medium supplemented with $0.1 \mathrm{mg} \mathrm{L}^{-1}$ IBA was also appropriate for rhizogenesis of $C$. forskohlii plants (Fig. 1b). The experiments showed that examined nutrient media containing IAA and IBA accelerated root formation and each plant forming about 2-3 branches.
The covering with polyethylene membranes for two weeks of planted to plastic pots with the mixture substrate well-rooted $C$. forskohlii plantlets led to high levels of relative humidity which enhanced the initial survival of the potted plants. A positive effect of mixture substrate consisting soil:peat:sand in a 2:1:1 ratio, on plant growth and development, was observed through the first week after planting The growth and development of $C$. forskohlii plants during their acclimatisation was a sign of successful ex vitro adaptation. The used nutrient medium influenced 
the survival rate and growth parameters of the plants. Among the four tested nutrient media, the highest percentage of survival $(93.3 \%)$ was observed in plants derived from $1 / 2$ MS medium supplemented with $0.1 \mathrm{mg} \mathrm{L}^{-1}$ IAA (Tables 2, Fig 1e). This medium had a beneficial effect on the growth and development of the plant, which reached the maximum height and formed the highest number of leaves.

\begin{tabular}{lccc} 
Table 2 Influence of the IBA and IAA on the survival of $C$. forskohlii plants on mixture substrate after two months \\
\hline Mixture substrate (soil:peat:sand, & Plant survival, & Plant height, & Number of leaves, plant ${ }^{-1}$ \\
$2: 1: 1, \mathrm{v} / \mathrm{v} / \mathrm{v})$ & $\%$ & $\mathrm{~cm}$ & $1.50 \pm 0.375^{\mathrm{b}}$ \\
$1 / 2 \mathrm{MS}+0.1 \mathrm{mg} \mathrm{L}^{-1} \mathrm{IBA}$ & 78.6 & $5.50 \pm 0.275^{\mathrm{a}}$ & $18 \pm 0.9^{\mathrm{b}}$ \\
$1 / 2 \mathrm{MS}+0.5 \mathrm{mg} \mathrm{L}^{-1} \mathrm{IBA}$ & 78.6 & $9.50 \pm 0.475^{\mathrm{c}}$ & $16 \pm 0.8^{\mathrm{a}}$ \\
$1 / 2 \mathrm{MS}+0.1 \mathrm{mg} \mathrm{L}^{-1} \mathrm{IAA}$ & 93.3 & $7.00 \pm 0.350^{\mathrm{b}}$ & $20 \pm 1.0^{\mathrm{c}}$ \\
$1 / 2 \mathrm{MS}+0.5 \mathrm{mg} \mathrm{L}^{-1} \mathrm{IAA}$ & 86.7 & 0.707244 & $16 \pm 0.8^{\mathrm{a}}$ \\
\hline LSD & & 1.65487 \\
\hline
\end{tabular}

It was found that $86.7 \%$ of plants cultured on MS medium containing $0.5 \mathrm{mg} \mathrm{L}^{-1}$ IAA survived. In contrast, the plants derived from $1 / 2 \mathrm{MS}$ media with the addition of 0.5 and $0.1 \mathrm{mg} \mathrm{L}^{-1}$ IBA showed a lower survival rate (about 78.6\%). The plants from all studied variants were characterized by fast growth, have 2-3 branches and big green leaves from all media (Fig. 1f).

\section{Antioxidant capacity}

A concomitant increase in the enzyme activity (SOD, CAT, APX and GPO activity) was observed in $C$. forskohlii shoots and roots with increasing the concentration of IBA or IAA in the MS nutrient medium (Fig. 2).
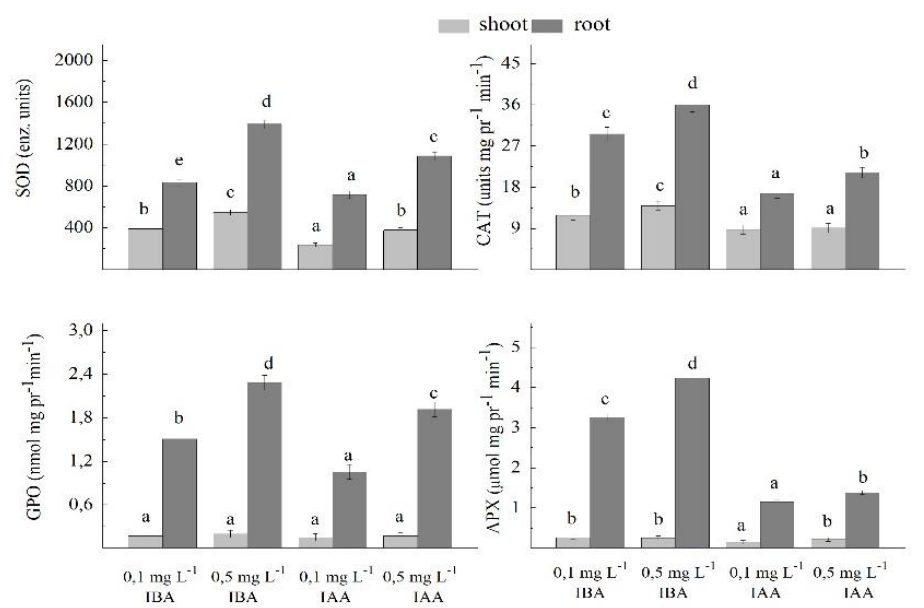

Figure 2 The activity of antioxidant enzymes superoxide dismutase (SOD), catalase (CAT), guaiacol peroxidase (GPO), and ascorbate peroxidase (APX) in the in vitro propagated Coleus forskohlii shoot and root. Values are means $\pm \mathrm{SE}$, $\mathrm{n}=3$; different letters indicate significant differences assessed by Fisher LSD test $(\mathrm{P} \leq 0.05)$ after performing ANOVA multi-factor analysis.

The antioxidant enzymes activity was higher when for C. forskohli micropropagation was realized with IBA applying in comparison with IAA Similar to the enzyme antioxidant defence system, the non-enzymes antioxidan power showed higher content of metabolites with antioxidant capacity (total phenol content, total flavonoids content, WS- and LS-metabolites) in in vitro propagated C. forskohlii roots than in shoots (Fig. 3).

The greatest difference in plant organs was measured in the total flavonoids conten wherein the roots values are significantly higher than those in the aboveground parts. The results for radical scavenging activity (DPPH method) indicate significant differences in the ability to scavenge free radicals of methanol extracts from shoots from micropropagated $C$. forskohlii plants with adding of IAA in MS nutrient medium with both concentrations (Fig. 3). There were no significan differences in radical scavenging activity in the extract from $C$. forskohlii roots in vitro propagated with both tested auxins. Among all the extracts of in vitro derived plants from various PGRs containing MS media, the highest ferric ion-reducing power (FRAP method) was observed in methanol extract of $C$. forskohlii plantlets obtained from MS medium supplemented with $0.5 \mathrm{mg} \mathrm{L}^{-1}$ IAA. This was followed by the methanol extracts activity of plantlets from $0.1 \mathrm{mg} \mathrm{L}^{-1}$ IAA. The values for the total antioxidant capacity of extract from plantlets grow at MS supplemented with $0.1 \mathrm{mg} \mathrm{L}^{-1} \mathrm{IBA}$ was the lowest in comparison with all extracts of in vitro propagated plantlets.

\section{DISCUSSION}

In the present study, in vitro rooting of $C$. forskohlii was attempted using 0.5 and $0.1 \mathrm{mg} \mathrm{L}^{-1}$ IBA and IAA. The obtained results suggest that two investigated auxins could be used separately in $1 / 2$ MS medium for rooting of $C$. forskohlii, but IAA in concentration $0.1 \mathrm{mg} \mathrm{L}^{-1}$ being more effective to produce plants with welldeveloped roots which were easily adapted in mixture substrate contained soil:peat:sand in a $2: 1: 1$ ratio.

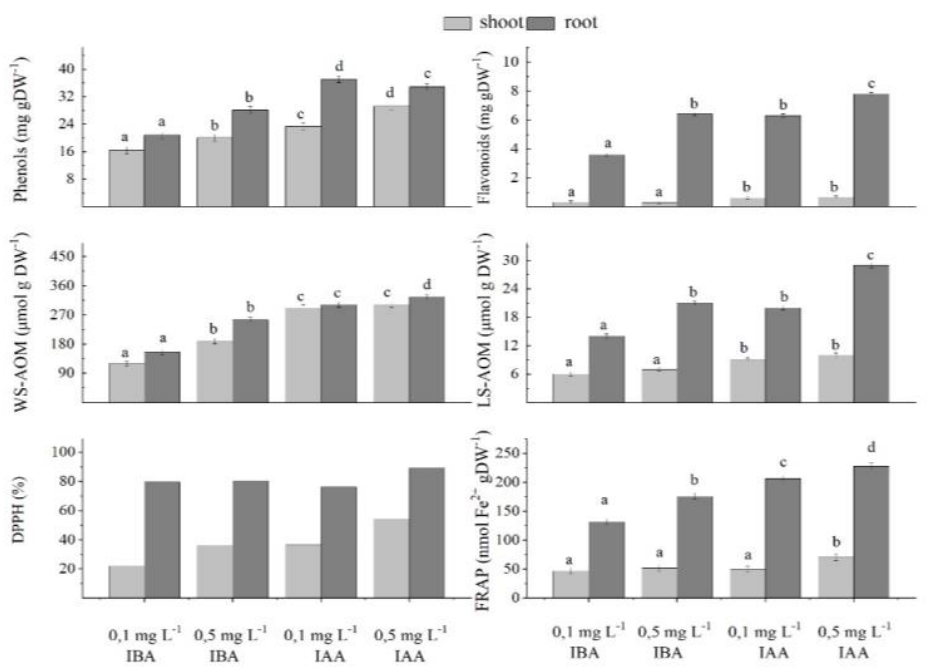

Figure 3 Antioxidant potential and content of metabolites with antioxidant power in the in vitro propagated Coleus forskohlii shoot and root. Values are means $\pm \mathrm{SE}$, $\mathrm{n}=3$; different letters indicate significant differences assessed by Fisher LSD test $(\mathrm{P} \leq 0.05)$ after performing ANOVA multi-factor analysis.

Both factors availability of well-developed roots as well as humidity control are of great necessary precondition for the success of ex vitro plantlets acclimatization. The choice of optimal rooting medium and appropriate auxin for adventitious root formation can improve the ex vitro acclimatization of micro plants. IAA was the most effective and appropriate auxin for the induction and development of roots This was verified by the higher rooting percentage as well as the number of roots formed per explant. The other authors (Sharma et al., 1991; Bhattacharyya and Bhattacharya, 2001; Assamenew and Narayanaswamy, 2004) also confirmed the positive effect of IAA on in vitro rooting of $C$. forskohlii shoots. The best in vitro development of roots was reported when the micropropagated shoots were transferred for growing to MS medium containing IAA $\left(1.0 \mathrm{mg} \mathrm{L}^{-1}\right)$ (Sharma et al., 1991) or 1 ppm IAA (Assamenew and Narayanaswamy, 2004). They did not show any morphological abnormality when compared with the original donor plants and the frequency of rooting was $100 \%$ (Bhattacharyya and Bhattacharya, 2001). In our experiment, auxin IAA at low concentration $(0.1 \mathrm{mg}$ $\left.\mathrm{L}^{-1}\right)$ in a half-strength MS medium with lower sucrose content $(2.0 \%)$ increased both the frequency of developed shoots and the number of roots per shoot. This nutrient medium induced (2-3) shoots per explant. In addition, the micro plants grew in height $(10.2 \mathrm{~cm})$ within 3 weeks and were cut into 3-4 nodal segments and again subcultured on fresh media. So that expensive cytokinins are not necessary for micropropagation. The protocol that was developed is simple and low-cost and could be used for large-scale plant production. Jan et al. (2009) also developed in vitro method for micropropagation of medicinal plant Picrorhiza kurroa without using cytokinin. Our research confirmed Hussey (1982) hypothesis that some plant species do not need high levels of exogenous hormones for plant regeneration because they have enough endogenous growth regulators. For removing, neutralizing and scavenging the reactive oxygen species, micropropagated $C$. forskohlii roots maintained a significant higher enzyme antioxidant protection system (SOD, CAT, APX and GPO activity) than shoot under both auxins IBA and 
IAA treatments. With increasing the concentration of IBA or IAA in the MS nutrient medium, a significant increase in the level of enzyme activity was observed in shoots and roots. In contrast to the present study, it has been reported higher activity in roots than in shoots only for CAT, while regarding SOD activity there is no significant difference, about GPX the activity is higher in leaves during micropropagation of Elephantopus scaber L (Rout and Sahoo, 2013). A significant increase in SOD activity as compared to POX and CAT during Asiatic hybrid lily root formation has been reported, while POX and CAT enzymes decreased during shoot formation (Misra et al., 2010). The results confirm that different medicinal plants respond differently to stressful conditions and have developed their specific response(s) against each of these stresses as well as crossstress response.

Different plants require different solvent types for maximum extraction of antioxidant metabolites. Wong et al. (2006) studied the influence of the solven type used for extraction on the antioxidant capacity of 30 medicinal plants. The authors have established that water extracts of 23 medicinal plants have antioxidan activity higher than the methanol extracts. Bhebhe et al. (2016) have reported that $50 \%$ acetone could extract the highest total phenol content from Camellia sinensis, Lippia javanica, and Ilex paraguariensis, whereas, $50 \%$ of ethanol is required to get the highest total phenol content from Cuphea carthagenensis. According to Ibrahim et al. (2018), methanol extracts from in vitro propagated Plectranthus barbatus exhibited higher antioxidant activity including total phenol and tota flavonoids content and DPPH radical scavenging activity than hexane extracts Therefore, we chose to use methanol for extraction in our experiments. The phenolic compounds have the ability to scavenging the free radicals by giving up hydrogen atoms from their hydroxyl groups to the radicals to form stable phenoxyl radicals, therefore measuring the amount of phenolic compounds is of great importance for determining the antioxidant capacity of plant extracts (Canadanovic-Brunet et al., 2005). The three weeks cultivated $C$. forskohlii plantlets on MS medium supplemented with $0.5 \mathrm{mg} \mathrm{L}^{-1}$ IAA showed the highest total phenol content in shoots and roots. The results also indicated that, increasing the concentration of the auxins IBA and IAA in the MS nutrient medium lead to increasing the antioxidant metabolites content in $C$. forskohlii. A higher level of total phenolic accumulation in Orthosiphon stamineus has been reported as the concentration of ABA increased (Ibrahim and Jaafar, 2013). Bota and Deliu (2015) found that different combinations and concentrations of cytokines and auxins strongly stimulated the production of flavonoids in cell suspension cultures of Digitalis lanata. Oxygen radical absorbance capacity is a widely used hydrogen atom transfer-based method that measures the antioxidant capacity of natural products. The radical scavenging activity (DPPH method) and ferric reducing antioxidant power (FRAP method) assay, simple tests of the total antioxidan power have been select to assess the presumable effects of the plant growth regulators on the antioxidant capacity in roots and shoots methanol extract from in vitro propagated $C$. forskohlii plantlets. Plants micropropagated on MS medium with adding IBA or IAA showed the same trend of change of the ferric ion reducing activities as the content of total phenol and flavonoids in the methanol extract. Our results are in agreement also with a previous report where a positive correlation between high total phenol and flavonoids content and antioxidan activities in Artemisia absinthium L. was reported (Canadanovic-Brunet, 2005).

\section{CONCLUSION}

In conclusion, the economic method for in vitro cultivation of $C$. forskohlii was developed using a low-cost half-strength MS medium with lower sucrose conten $(2.0 \%)$. The effectiveness of rooting depends on the auxins used. The highest frequency of rooting and root number with the highest length were achieved on the $1 / 2 \mathrm{MS}$ medium containing $0.1 \mathrm{mg} \mathrm{L}^{-1}$ IAA. The plants revealed good adaptability ex vitro on a potting mixture consisting of soil:peat:sand (2:1:1 v/v/v) and $95 \%$ of them developed normally. Plants looked healthy and no phenotypic variations among them were observed. s. Stress conditions during shoot induction of Coleus forskohlii may have stimulated polyphenol production, It is evident from our study that auxins IAA and IBA influence secondary metabolite production. The total phenol and flavonoids content in the methanolic extract of micropropagated coleus plantlets organs (roots and shoots) derived from $1 / 2 \mathrm{MS}$ medium containing $0.5 \mathrm{mg}$ $\mathrm{L}^{-1}$ IAA were responsible for the highest total antioxidant activity in both assays tested. Based on the current findings, we conclude that $1 / 2$ MS medium supplemented with $0.5 \mathrm{mg} \mathrm{L}^{-1}$ IAA yields high total phenol and flavonoids content as well as higher antioxidant activity (radical scavenging activity and ferric reducing antioxidant power). The formation rate of enzyme and non-enzyme defence systems depends on the auxin IBA and IAA levels into the medium. The obtained results give a basis for future investigation on the impact of different plant growth regulators on the gene expression of key enzymes connected with the antioxidant defence system.

Acknowledgements: This study was conducted with a partially supported project by international scientific cooperation between Bulgarian Academy of Sciences and National Research Centre - Egypt. The authors are thankful to Madlen Boychinova, Mariana Sichanova and Janet Mincheva for excellent technical assistance.

\section{REFERENCES}

Amoo, S. O. \& Van Staden, J. (2013). Influence of plant growth regulators on shoot proliferation and secondary metabolite production in micropropagated Huernia hystrix. Plant. Cell Tissues and Organ Culture, 112, 249-256. https://doi.org/10.1007/s11240-012-0230-x

Assamenew, T. \& Narayanaswamy, M. P. (2004). In vitro shoot multiplication and rooting in Coleus forskohlii Briq. Plant Biotechnology: Principles and Application AGRIS Rec. 4, 126-134. https://agris.fao.org/agrissearch/search.do?recordID=ET2005000016

Benson, E. E., 1990. Free Radical Damage in Stored Plant Germplasms. Int. Board Plant Gen. Res., Rome. ISBN 13: 978-92-9043-196-1

Benzie, I. \& Strain, J. (1996). The ferric reducing ability of plasma (FRAP) as a measure of "antioxidant power": the FRAP assay. Analitical Biochemistry, 239, 70-76. https://doi.org/10.1006/abio.1996.0292

Bhattacharyya, R. \& Bhattacharya, S. (2001). In vitro multiplication of Coleus forskohlii Briq.: an approach towards shortening the protocol. In Vitro Cellular \& Developmental Biology - Plant, 37, 572-575. https://doi.org/10.1007/s11627-0010100-4

Bhebhe, M., Fuller, T. N., Chipurura, B. \& Muchuweti, M. (2016). Effect of solvent type on total phenolic content and free radical scavenging activity of black tea and herbal infusions. Food Analytical Methods, 9, 1060-1067. https://doi.org/10.1007/s12161-015-0270-z

Bota, C. \& Deliu, C. (2015) Effect of plant growth regulators on the production of flavonoids by cell suspension cultures of Digitalis lanata. Farmacia, 63, 716-719. http://www.revistafarmacia.ro/201505/art-15-Bota_Deliu_716-719.pdf

Bradford, M.M. (1976). A rapid and sensitive method for the estimation of microgram quantities of protein utilizing the principle of protein-dye binding Analytical Biochemistry, 72, 248-254. https://doi.org/10.1016/00032697(76)90527-3

Canadanovic-Brunet, J. M., Djilas, S. M. \& Cetkovic, G. S. (2005). Free-radical scavenging activity of wormwood (Artemisia absinthium) extracts. Journal of Sciences of Food and Agriculture, 85, 265-272. https://doi.org/10.1002/jsfa.1950 Gaspar, T., Kevers, C., Penel, C., Greppin, H., Reid, D. \& Thorpe, T. (1996). Plant hormones and plant growth regulators in plant tissue culture. In Vitro Cell Developmental Biology - Plant, 32, 272-289. https://doi.org/10.1007/BF02822700 George, E. F., Hall, M. A. \& De Klerk, G. -J. (2008). Plant growth regulators II: cytokinins, their analogues and antagonists, In: George, E. F., Hall, M. A., De Klerk, G. -J., (Eeds), Plant propagation by tissue culture, Springer, Netherlands, pp. 205-226. https://doi.org/10.1007/978-1-4020-5005-3_6

Giannopolitis, C. N. \& Ries, S. K. (1977). Superoxide dismutases I. Occurrence in higher plants. Plant Physiology, 59, 309-314. https://doi.org/10.1104/pp.59.2.309 Hristozkova, M., Geneva, M., Stancheva, I., Iliev, I. \& Azcon-Aguilar, C. (2017). Symbiotic association between golden berry (Physalis peruviana) and arbuscular mycorrhizal fungi in heavy metal-contaminated soil. Journal of Plant Protection Researches, 57, 173-184. https://doi.org/10.1515/jppr-2017-0024

Hussey, G. (1982) In vitro propagation of monocotyledonous bulbs and corms. Proc. 5th Intl. Cong. Plant Tissue Cell Culture. pp. 677 - 680

Ibrahim, M. H. \& Jaafar, H. Z. (2013). Abscisic acid induced changes in production of primary and secondary metabolites, photosynthetic capacity, antioxidan capability, antioxidant enzymes and lipoxygenase inhibitory activity of Orthosiphon stamineus Benth. Molecules, 18, 7957-7976. https://doi.org/10.3390/molecules18077957

Ibrahim, M. M., Arafa, N. M. \& Aly, U. I. (2018). Antioxidant activity, phenol and flavonoid contents of plant and callus cultures of Plectranthus barbatus Andrews. $\begin{array}{llll}\text { Egyptian } & \text { Pharmaceutical } & \text { Journal, } & 17,\end{array}$ https://doi.org/10.4103/epj.epj_38_17

Jamwal, K., Bhattacharya, S. \& Puri, S. (2018). Plant growth regulator mediated consequences of secondary metabolites in medicinal plants. Journal of Applied Research on Medicinal and Aromatic Plants, 9, 26-38. https://doi.org/10.1016/j.jarmap.2017.12.003

Jan, A., Phalisteen, S., Thomas, G. T. \& Shawl, A. S. (2009). Auxin prompted improved micropropagation protocol of Picrorhiza kurroa: an endangered medicinal plant. Plant Tissue Culture and Biotechnology, 19(2), 161-167. https://doi.org/10.3329/ptcb.v19i2.5433

Kamini, K., Ashashri, S. \& Lalit, G.P.N. (2013). Comprehensive review: Coleus forskohlii. International Journal Of Ayurvedic And Herbal Medicine, 3, 1106 1113. https://doi.org/10.31142/ijahm

Lagrimini, M., Gingas, V., Finger, F., Rothstein, S. \& Liu, T. -T.Y. (1997) Characterization of antisense transformed plants deficient in the tobacco anionic peroxidase' L. Plant Physiology, $114 \quad$ (4): 1187-1196, https://doi.org/10.1104/pp.114.4.1187

Larson, R. A. (1988). The antioxidants of higher plants. Phytochemistry, 27, 969 978. https://doi.org/ 10.1016/0031-9422(88)80254-1

Misra, P., Pandey, V. \& Kochhar, S. (2010). Study of antioxidant enzymes activity during organogenesis and in vitro propagation of Asiatic Hybrid Lily. Journal of Plant Biochemistry and Biotechnology, 19, 119-122. https://doi.org/10.1007/BF03323449 
Murashige, T. \& Skoog, F. (1962). A revised medium for rapid growth and bio assays with tobacco tissue cultures. Physiologia Plantarum, 15, 473-497. https://doi.org/10.1111/j.1399-3054.1962.tb08052.x

Nair, A. J., Sudhakaran, P. R., Madhusudana, J. R. \& Ramakrishna, S. V. (1992)

Berberine synthesis by callus and cell suspension cultures of Coscinium fenestratum. Plant Cell, Tissue and Organ Culture, 29, 7-10. https://doi.org/10.1007/BF00036139

Nakano, Y. \& Asada, K. (1987). Purification of ascorbate peroxidase in spinach chloroplasts: its inactivation in ascorbate-depleted medium and reactivation by monodehydroascorbate radical. Plant Cell Physiology, 28, 131-140. https://doi.org/10.1093/oxfordjournals.pcp.a077268

Pfeffer, H., Dannel, F. \& Römheld, V. (1998). Are there connection between phenol metabolism, ascorbate metabolism and membrane integrity in leaves of boron-deficient sunflower plants?. Physiologia Plantarum, 104(3), 479-485. https://doi.org/10.1034/j.1399-3054.1998.1040325.x

Praveena, R., Pandian, A. S. \& Jegadeesan, M. (2012). In vitro propagation studies on Coleus forskohlii Briq. - A medicinal plant. International Journal of Pharma and Bio Sciences, 3, 82-92. https://ijpbs.net/details.php?article=1125

Prieto, P., Pineda, M. \& Aguilar, M. (1999). Spectrophotometric quantitation of antioxidant capacity through the formation of a phosphomolybdenum complex: specific application to the determination of vitamin E. Analytical Biochemistry, 269, 337-341. https://doi.org/10.1006/abio.1999.4019

Rao, R. S. \& Ravishankar, G. A. (2002). Plant tissue cultures; chemical factories of secondary metabolites. Biotechnology Advances, 20, 101-153. https://doi.org/10.1016/s0734-9750(02)00007-1

Rout, J. R. \& Sahoo, S. L. (2013). In vitro propagation and antioxidant enzymes activities of Elephantopus scaber L. Asia-Pacific Journal of Molecular Biology and Biotechnology, 21, 59-66. http://www.myjurnal.my/public/articleview.php?id=76763

Sharma, N., Chandel, K. P. \& Srivastava, V. K. (1991). In vitro propagation of Coleus forskohlii Briq., a threatened medicinal plant. Plant Cell Reproduction, 10, 67-70. https://doi.org/10.1007/BF00236459

Tepe, B., Sokmen, M., Akpulat, H. A. \& Sokmen, A. (2006). Screening of the antioxidant potentials of six Salvia species from Turkey. Food Chemistry, 95, 200204. https://doi.org/10.1016/j.foodchem.2004.12.031

Wagh, V. D., Patil, P. N., Surana, S. J. \& Wagh, K. V. (2012). Forskolin: upcoming antiglaucoma molecule. Journal of Postgraduate Medicine, 58, 199-202. https://doi.org/10.4103/0022-3859.101396

Wong, C. C., Li, B. H., Cheng, W. K. \& Chen, F. (2006). A systematic survey of antioxidant activity of 30 Chinese medicinal plants using the ferric reducing antioxidant power assay. Food Chemistry Journal, 97, 705-711. https://doi.org/10.1016/j.foodchem.2005.05.049

Zayova, E., Geneva, M., Stancheva, I., Dimitrova, L., Petrova, M., Hristozkova, M. \& Salamon, I. (2019). Evaluation of the antioxidant potential of in vitro propagated hyssop (Hyssopus officinalis L.) with different plant growth regulators. Medicinal Plants - International Journal of Phytomedicines and Related Industries, 10, 261-270. https://doi.org/10.5958/0975-6892.2018.00044.8

Zayova, E., Stancheva, I., Geneva, M., Hristozkova, M., Dimitrova, L., Petrova, M., Sichanova, M., Salamon, I. \& Mudroncekova, S. (2018). Arbuscular mycorrhizal fungi enhance antioxidant capacity of in vitro propagated garden thyme (Thymus vulgaris $\quad$ L.). Symbiosis, 74, 177-187. https://doi.org/10.1007/s13199-017-0502-7

Zhishen, J., Mengcheng, T. \& Jianming, W. (1999). The determination of flavonoid contents in mulberry and their scavenging effects on superoxide radicals. Food Chemistry Journal, 64, 555-559. https://doi.org/10.1016/S0308 8146(98)00102-2

Upadhyaya A., Sankhla D., Davis T. D., Sankhla N. \& Smith B. N. (1985). Effect of paclobutrazol on the activated oxygen metabolism and lipid peroxidation in senescing soybean leaves. Journal of Plant Physiology, 121 (5): 453-61. https://doi.org/10.1016/S0176-1617(85)80081-X 